\title{
Modeling in Healthcare: Selection of Simulation Types
}

\author{
Mohd Kamal Mohd Nawawi ${ }^{1,2, *}$, Jafri Zulkepli ${ }^{1}$, Ruzelan Khalid ${ }^{1,2}$, Norhaslinda Zainal Abidin ${ }^{1,2}$ \\ ${ }^{1}$ School of Quantitative Sciences, Universiti Utara Malaysia, 06010 UUM Sintok, Kedah, Malaysia \\ ${ }^{2}$ Institute of Strategic Industrial Decision Modelling (ISIDM), Universiti Utara Malaysia, 06010 UUM Sintok, Kedah, Malaysia
}

Received August 30, 2021; Revised November 2, 2021; Accepted November 18, 2021

\section{Cite This Paper in the following Citation Styles}

(a): [1] Mohd Kamal Mohd Nawawi, Jafri Zulkepli, Ruzelan Khalid, Norhaslinda Zainal Abidin , "Modeling in Healthcare: Selection of Simulation Types," Universal Journal of Public Health, Vol. 9, No. 6, pp. 401 - 409, 2021. DOI: 10.13189/ujph.2021.090607.

(b): Mohd Kamal Mohd Nawawi, Jafri Zulkepli, Ruzelan Khalid, Norhaslinda Zainal Abidin (2021). Modeling in Healthcare: Selection of Simulation Types. Universal Journal of Public Health, 9(6), 401 - 409. DOI: 10.13189/ujph.2021.090607.

Copyright $@ 2021$ by authors, all rights reserved. Authors agree that this article remains permanently open access under the terms of the Creative Commons Attribution License 4.0 International License

\begin{abstract}
The nature of the healthcare system is crucial and requires health authorities worldwide to ensure every decision is made correctly and efficiently. Simulation modeling which is among the decision-making techniques, is generally used to represent the real systems of healthcare for the authorities to evaluate prior to any modification. A holistic understanding of the issues related to simulation types in healthcare is required. This paper reviews and summarizes publications related to various types of computer simulation tools in the healthcare domain, using the Scopus database. Based on healthcare applications and issues, this paper finalized five main types of simulations: 1 ) discrete-event simulation; 2) system dynamics; 3) agent-based modeling; 4) Monte Carlo simulation; and 5) hybrid systems. All of these types have continued to contribute to healthcare simulation modelling in recent years and more are expected in the future. In general, this review argues that future studies should focus on framework development that will support the selection of simulation types based on the problem.
\end{abstract}

Keywords Healthcare, Discrete-Event Simulation, System Dynamics, Agent-Based Modeling, Monte Carlo Simulation, Hybrid Systems

\section{Introduction}

Modeling is one method for examining how real-world systems operate. It depicts and demonstrates how a specific system is interconnected with other systems in its environment. There are numerous modeling techniques for representing real-world systems. To model the integration of health and social care in healthcare systems, two types of modeling techniques have been widely used: simple modeling business process technique and simulation technique.

The simple modeling business process becomes a useful technique to picture the entire system of how it works, with the healthcare and social care model being no exception. Most simple business process models take a long time to develop before they reach a conclusion about whether or not to adapt the system. It necessitates a significant financial investment.

A simple business process model functions in the same way that a modeling does. It examines how the entire system operates and generates a framework or flow chart of the system. If the current systems are not performing well, the modeler will usually add some features or make improvements to the systems. After the setup or installation is complete, the experiment will begin. The experiment will take some time to complete. At the end of the experiment, the decision maker will have three options: continue with the current system, continue with the current system with some adjustments, or terminate the system entirely. Everything is dependent on the outcome of the experiment. 
Many researchers, including Sobolev [1], Walshe and Rundall [2], and Watt et al. [3], have stated that healthcare management should understand the impact or consequences of every decision they make before implementing it in the real world, because healthcare is a zero-tolerance sector for errors. As a result, the care sectors should seek or use tools that can provide a comprehensive view of any decision made by decision makers.

Given the limitations of simple business process modeling techniques, modelers are increasingly turning to simulation techniques. The main distinction between a simple business process model and a simulation is the process of experimentation until they reach a conclusion and make a decision on which initiative to implement. The model for a simple business process is implemented in the real world before experimentation, whereas the model for a simulation technique is built in a computer and the experimentation is done using computer simulation before implementation. The main advantage of the simulation technique is that it can mimic the dynamics of the real system [4].

\subsection{Theoretical Background}

As the premier international forum for disseminating recent advances in the field of system simulation, since 1967, Winter Simulation Conference (WSC) is one of the most prestigious simulation conferences [5]. However, the application of computer simulation in healthcare only started to be presented in WSC in the early 1990s. Among the earliest authors are Iskander and Carter [6] and Draeger [7] using discrete event simulation, Canner et al. [8] and Roberts [9] using Monte-Carlo simulation. Since then, more simulation applications and techniques have been discovered.

The simulation method consists of various techniques. These techniques have been used for a number of purposes in a variety of industries. Kuljis et al. [10] suggest how these techniques could be used in the healthcare sector. Table 1 shows how simulation techniques have been used in various industries for a variety of purposes, including how these techniques can be used in the healthcare industry.

Table 1. Simulation techniques applied in different industries and potential use in the healthcare sector (adapted from Kuljis et al. [10])

\begin{tabular}{|c|c|c|}
\hline Sector/industry & Purpose of application & Application to healthcare sector \\
\hline Manufacturing & $\begin{array}{l}\text { Enhancements to the manufacturing process, inventory management, and } \\
\text { new product development }\end{array}$ & \multirow{16}{*}{$\begin{array}{l}\text { - Logistics services } \\
\text { - } \text { Reengineering and management } \\
\text { - } \text { Reduction of waiting times } \\
\text { - Resource and asset allocation and } \\
\text { management } \\
\text { - Patient pathway design and } \\
\text { management } \\
\text { - Management of strategic and } \\
\text { - } \text { operational aspects } \\
\text { - Mange management } \\
\text { - Healthement of demand and supply } \\
\text { - Analysis of risk } \\
\text { - Management of risk } \\
\text { - Decision making/support under } \\
\text { conditions of uncertainty (e.g. in } \\
\text { commissioning procurement, policy } \\
\text { making, organizational change etc.) }\end{array}$} \\
\hline \multirow{2}{*}{ Automobile } & Improvements in the production process & \\
\hline & New product development & \\
\hline \multirow{6}{*}{ Construction } & Logistics and operations, construction scheduling & \\
\hline & Training, real-time planning, resource allocation & \\
\hline & $\begin{array}{l}\text { Incentives and disincentives-based contracting, construction scheduling, } \\
\text { risk modeling }\end{array}$ & \\
\hline & Supply chain simulation & \\
\hline & Training, improving communication skills, and conveying concepts & \\
\hline & Construction scheduling, risk modeling & \\
\hline \multirow{4}{*}{ Energy } & Management of assets & \\
\hline & $\begin{array}{l}\text { Power trading, market place simulation, competitive strategy, expansion } \\
\text { planning }\end{array}$ & \\
\hline & $\begin{array}{l}\text { Emergency planning, energy pricing, power trading, market place } \\
\text { simulation, competitive strategy }\end{array}$ & \\
\hline & $\begin{array}{l}\text { Expansion planning, market place simulation, power trading, financial } \\
\text { analysis }\end{array}$ & \\
\hline Pharmacology & Improvement in production process, new product development & \\
\hline Process industry & Improvement in production process & \\
\hline Biotechnology & Growth projections & \\
\hline
\end{tabular}


Some of the policy makers, or modelers or "ORticians" use the decision tools, especially the simulation types, based on their expertise, not on the problem at hand. Chahal [11] names this "fitting the nail into the hammer". Some of the tools that have been used are not suitable enough to capture certain variables or cater to the problems at hand. Barton et al. [12] have developed a framework of choosing the right simulation tools based on the problem at hand. The main approaches to modeling used in economic evaluations in health care are decision trees, Markov models and individual sampling models. These methods assume the independence of individuals within the model. Where interaction between individuals is important, other methods such as discrete-event simulation or system dynamics are preferable. However, the developed framework lacks some of the other types of simulation methods, such as hybrid simulation, agent-based modeling (ABM) simulation, and mathematical modeling. The framework is also too general and can be confusing for decision makers or modelers to find the right and suitable decision tool based on the problem at hand. As their framework is too general and can be confusing for those who are novices in the simulation area, especially in the healthcare area, it would be beneficial to develop a specific framework that can be used as guidance in selecting the best and most suitable simulation tools or types based on the problem at hand, in the healthcare area.

Pidd [13] argued that it should depend on the problems for the researcher to choose a good approach to model the systems. There are three questions that should be asked by researchers before choosing the best technique to model the system, which are: what should be simulated, why to simulate and how to simulate [14].

This study first embarked on capturing information about the healthcare systems and their problems, and then compiling information gathered from previously developed healthcare models. Then, the specific characteristics of the problems against their suitable techniques based on the collection of gathered information are map. Simulation is an investigation technique in healthcare where the goals of a simulation vary in different projects: analysis of selected department load, policy making, building testbeds for the testing of various solutions, etc. [15].

Morecroft and Robinson [16] and Brailsford and Hilton [17] argue that studies about the difference between two dominant simulation techniques, system dynamics (SD) and discrete-event simulation (DES), are mostly biased as they are based on their personal opinions. There is no evidence collected from any empirical studies about the comparison between SD and DES [18].

\subsection{Research Questions}

The main question considered in this study is "What are the most widely used simulation types in healthcare?" This was further subdivided into three underlying research questions. Section 3 offers answers to all these questions.

RQ1: What are the approaches used in the existing literature on healthcare simulation modeling?

RQ2: What are the simulation types applied to healthcare systems published in impactful journal articles in recent years?

RQ3: Who are the main publication contributors in the area of healthcare simulation?

\section{Methodology}

This paper primarily employs the concept of systematic review [19] to identify real-world examples of how computer simulation techniques are used to solve problems in healthcare. The review process was conducted in August 2021. We used the Scopus database to search for related papers in healthcare and simulation techniques. The process began with a keyword search, as shown in Table 2. 
Table 2. Search string used for the review process and number of records.

\begin{tabular}{|c|c|}
\hline Keyword used & Number of records \\
\hline TITLE-ABS-KEY ( ( "simulation" ) AND ( "healthcare" ) ) & 10370 \\
\hline $\begin{aligned} & \text { TITLE-ABS-KEY ( ( "simulation" ) } \text { AND ( "healthcare" ) AND NOT ( "system dynamics" } \\
& \text { OR "discrete event" } \text { OR "agent based" } \\
&\end{aligned}$ & 8838 \\
\hline $\begin{array}{l}\text { TITLE-ABS-KEY ( ( "simulation" ) AND ( "healthcare" ) AND ( "system dynamics" OR } \\
\text { "discrete event" OR "agent based" OR "monte carlo") OR "hybrid" ) }\end{array}$ & 1765 \\
\hline $\begin{array}{c}\text { TITLE-ABS-KEY ( ( "simulation" ) AND ( "healthcare" ) AND ( "system dynamics" OR } \\
\text { "discrete event" OR "agent based" OR "monte carlo" ) ) }\end{array}$ & 1532 \\
\hline $\begin{array}{r}\text { TITLE-ABS-KEY ( ( "simulation" ) AND ( "healthcare" ) AND ( "system dynamics" OR } \\
\text { "discrete event" OR "agent based" ) ) }\end{array}$ & 1018 \\
\hline $\begin{array}{llll}\text { TITLE-ABS-KEY ( ( "simulation" ) } & \begin{array}{l}\text { AND ( "healthcare" ) AND ( "system dynamics" OR } \\
\text { "discrete event" ) ) }\end{array} \\
\end{array}$ & 792 \\
\hline TITLE-ABS-KEY ( ( "simulation" ) AND ( "healthcare" ) AND ( "system dynamics" ) ) & 219 \\
\hline $\begin{array}{l}\text { TITLE-ABS-KEY ( ( "framework" ) AND ( "simulation" ) AND ( "healthcare" ) AND } \\
\text { ( "system dynamics" OR "discrete event" OR "agent based" OR "monte carlo" ) OR } \\
\text { "hybrid" ) }\end{array}$ & 221 \\
\hline $\begin{array}{c}\text { TITLE-ABS-KEY ( ( "framework" ) AND ( "simulation" ) AND ( "healthcare" ) AND } \\
\text { ( "system dynamics" ) ) }\end{array}$ & $\begin{array}{c}39 \\
22 \text { (from 2015) } \\
10 \text { journal articles } \\
\end{array}$ \\
\hline $\begin{array}{l}\text { TITLE-ABS-KEY ( ( "framework" ) AND ( "simulation" ) AND ( "healthcare" ) AND } \\
\text { ( "discrete event" ) ) }\end{array}$ & $\begin{array}{c}86 \\
54 \text { (from 2015) } \\
26 \text { journal articles }\end{array}$ \\
\hline $\begin{array}{c}\text { TITLE-ABS-KEY ( ( "framework" ) AND ( "simulation" ) AND ( "healthcare" ) AND } \\
\text { ( "monte carlo" ) ) }\end{array}$ & $\begin{array}{c}37 \\
28 \text { (from 2015) } \\
26 \text { journal articles }\end{array}$ \\
\hline $\begin{array}{c}\text { TITLE-ABS-KEY ( ( "framework" ) AND ( "simulation" ) AND ( "healthcare" ) AND } \\
\text { ( "agent based" ) ) }\end{array}$ & $\begin{array}{c}59 \\
38 \text { (from 2015) } \\
14 \text { journal articles } \\
\end{array}$ \\
\hline 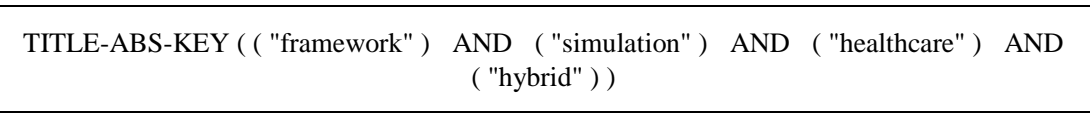 & $\begin{array}{c}53 \\
43 \text { (from 2015) } \\
14 \text { journal articles }\end{array}$ \\
\hline
\end{tabular}

Several words we used to search for articles that relate to simulation in healthcare, such as "healthcare", "discrete event simulation", "system dynamics", "agent based model", "simulation", "computer simulation" and so forth. Some of the words we combine together using the operator "and". More than 10,000 articles appear in the Scopus database. We then filtered the searching criteria to make it much smaller using the inclusion and exclusion criteria as shown in Table 3.

Table 3. The Inclusion and Exclusion Criteria

\begin{tabular}{|c|c|c|}
\hline Criteria & Inclusion & Exclusion \\
\hline Literature type & $\begin{array}{c}\text { Journal (research } \\
\text { articles) }\end{array}$ & $\begin{array}{c}\text { Book series, chapter in } \\
\text { books, conference } \\
\text { proceedings }\end{array}$ \\
\hline $\begin{array}{c}\text { Publication } \\
\text { timeline }\end{array}$ & $2015-2021$ & 2014 and before \\
\hline Language & English & Non-English \\
\hline $\begin{array}{c}\text { Nature of the } \\
\text { study }\end{array}$ & $\begin{array}{c}\text { Computerized } \\
\text { simulation }\end{array}$ & $\begin{array}{c}\text { Role-play and in situ } \\
\text { simulation }\end{array}$ \\
\hline
\end{tabular}

We select articles for specific years, i.e., 2015 to 2021, assuming that recent papers refer to previous papers. Therefore, the techniques to solve the same problem highlighted were using the same method or techniques. All theoretical papers or papers that do not have any discussion of the results were excluded. The selected articles must be in the healthcare area only and apply any modeling and simulation techniques, either single or hybrid techniques, as long as they have used at least one simulation technique.

However, these articles were then filtered again, to select only articles that had discussion about their results. We excluded articles that do not have the final result as we need to see whether the simulation technique used is suitable or not for the particular problem. The discussion about the result(s) can be interpreted as successful or unsuccessful. If the results have some problems (unsuccessful), then we consider that the particular technique was not suitable to use, and vice versa. All selected articles were reviewed thoroughly and all important criteria will be extracted. Such criteria are specific types of problems that researchers intend to solve, the method used and the results discussed. Based on the criteria that we have setup, we managed to get 15 articles that suit our objectives for this research. Generally, the simulations involved in the research are system dynamics, discrete event simulation, Monte Carlo simulation, and agent-based simulation. Some of the research combined these techniques with other techniques in operational research such as optimization to optimize whether the 
simulated results are fully optimized or not.

\section{Results and Discussion}

The analysis of the papers related to simulation types in healthcare can be categorized into five types. As depicted in Table 4, the types are DES, SD, ABM, Monte Carlo, and hybrid simulation.

\subsection{Discrete-Event Simulation}

Discrete event simulation (DES) is considered as the most widely used simulation type in healthcare. It provides a systematic approach to mimicking real systems at a micro level [20]. Even though DES is not a tool that will give the optimal solutions, "what if" scenarios could be analyzed in the model before modification or improvement is done to the real systems, especially in healthcare, which involves high risks or fatalities [20], [22]. Utilization of medical staff, including doctors and nurses, and waiting times and movements of patients are among the performance measures that are generally produced by DES [21]. DES usually comes together with queuing analysis since the performance measures of both techniques are similar [15], [23].

\subsection{System Dynamics}

System dynamics (SD), contradicts to DES is a highly abstract method of modeling. It ignores the fine details of a system, such as the individual properties of people, products, or events, and produces a general representation of a complex system. These abstract simulation models may be used for long-term, strategic modeling and simulation. Comparison of two or more models' performance based on certain metrics such as average inventory levels, lead time, and unfilled orders could be done by SD [24]. It is a method for understanding the behavior of complex social and economic systems at the macro or strategic level [26], [34].

\subsection{Agent-Based Modeling}

Relatively new compared to DES and SD, ABM basically consists of a group of independent individuals (agents) that interact with each other. Generally, ABM complements the limitations of DES by incorporating human behavior simulation and people-environment interactions [29]. Garcia-Magarino et al. [27] proposed an ABM to simulate people's movements on a smart bed with load sensors to define sleeping posture recognition algorithms. Liu et al. [28] stated that the complexity of the different pathways patients may take and the inherent uncertainty and variability of healthcare processes warranted a study. Therefore, ABM provides a flexible platform for studying ED operations, as it predicts system-level behavior from individual-level interactions [28].

Table 4. The Finding - The Selected Articles

\begin{tabular}{|c|c|c|c|c|c|}
\hline Authors & DES & SD & ABM & MC & Hybrid/ Applications \\
\hline Al-Hawari et al. [20] & $/$ & & & & Multi-criteria decision making \\
\hline Ordu et al. [21] & $/$ & $/$ & $/$ & & $\begin{array}{c}\text { Forecasting and mathematical } \\
\text { modeling hybrid with DES only }\end{array}$ \\
\hline Gul et al. [22] & $/$ & & & & Artificial neural network \\
\hline Kovalchuk et al. [15] & $/$ & & & & Queuing theory \\
\hline Li et al. [23] & $/$ & & & & Pareto optimization, Queuing theory \\
\hline Kochan et al. [24] & & $/$ & & & Supply chain management systems \\
\hline Bolt et al. [25] & $/$ & $/$ & & & DES and SD \\
\hline Kazemi et a. [26] & & $/$ & & & Smayesian belief network beds for data analytics \\
\hline Garcia-Magarino et al. [27] & & & $/$ & & Emergency department \\
\hline Liu et al. [28] & & & & & Emergency department \\
\hline Yousefi et al. [29] & & & & $/$ & Performance of proposed algorithm \\
\hline Alauddin et al. [30] & & & & Statistical analysis, \\
\hline Hassanhosseini et al. [31] & & & & & Sarkov chain \\
\hline Lee et al. [32] & & & & & \\
\hline Parolini et al. [33] & & & & & \\
\hline
\end{tabular}




\subsection{Monte Carlo}

A Monte Carlo simulation, quite different to the first three types of simulation, has been used in risk and statistical analysis [30], [31]. Lee et al. [32] built a Monte Carlo simulation study which shows that their proposed framework, in a range of data scenarios, performs better than their competitor analysis strategies. Normal Monte Carlo simulation normally involves data design and generation [33].

\subsection{Hybrid}

Each type of simulation has its own customized graphical approach, such as process flow for DES, causal loop diagrams for SD, and state diagrams for ABM [34]. Usually, hybridization of simulation types is used to combine both strategic and operational issues. Ordu et al. [21] combined DES with forecasting and optimization models, in a sequential flow. The outputs of forecasting were used as the inputs of the DES model, then the outputs from DES were used as inputs into the optimization model. Like DES, the performance of interest such as waiting times, length of stay, and duration of treatment was measured.

\subsection{Comparison and Analysis}

Additional analysis to longitudinally compare the simulation types was conducted in early November 2021. Extracted from the Scopus database, DES is the most published simulation type in healthcare modeling, with 646 publications. Figure 1 shows the frequency of all five simulation types since 1994 . The second most is MC simulation, with 547 publications, followed by hybrid (331 publications), ABM (299 publications) and lastly, SD (222 publications).

We then filtered the data to see the most recent publications in the most impactful publications, which covers publications in journal articles for the period of 2015 to 2021 as shown in Figure 2. Surprisingly, MC was found to have the highest number of publications, with 273 articles, compared to DES, with 224 articles, as shown in Figure 2. Other types are hybrid (131 articles), ABM (97 articles), and SD (73 articles).

In terms of the most contributing authors in the field of healthcare simulation, the top five authors are Tillal Eldabi (29 publications), Navonil Mustafee (26 publications), Adam Cheng (23 publications), Debra Nestel (23 publications) and Bruce Lee (22 publications). SD and hybrid systems were found to be the most popular simulation types used by the first two authors. Among the authors' most frequently cited publications are [34]-[39], which are based on hybrid types.

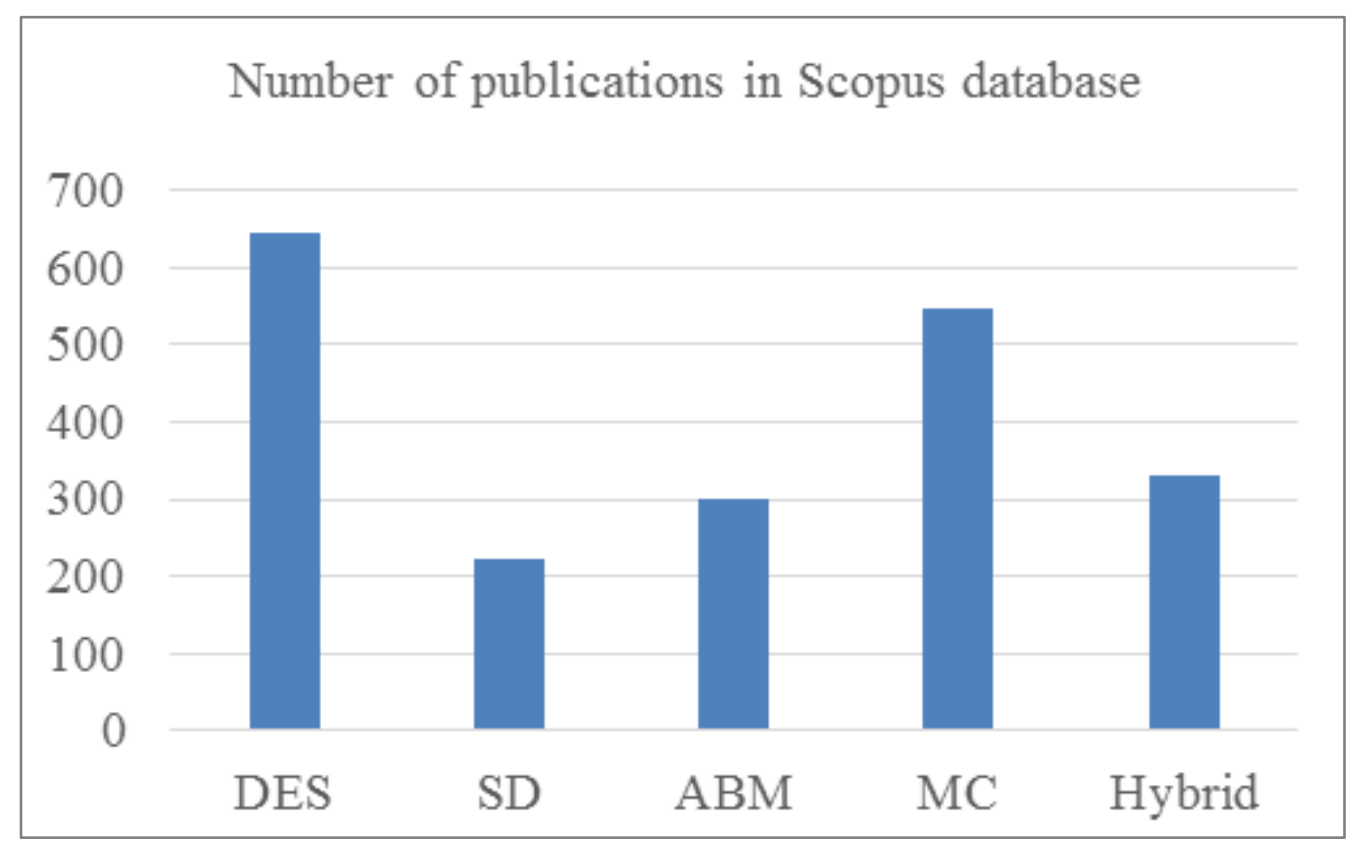

Figure 1. Frequency of the number of publications of five simulation types 


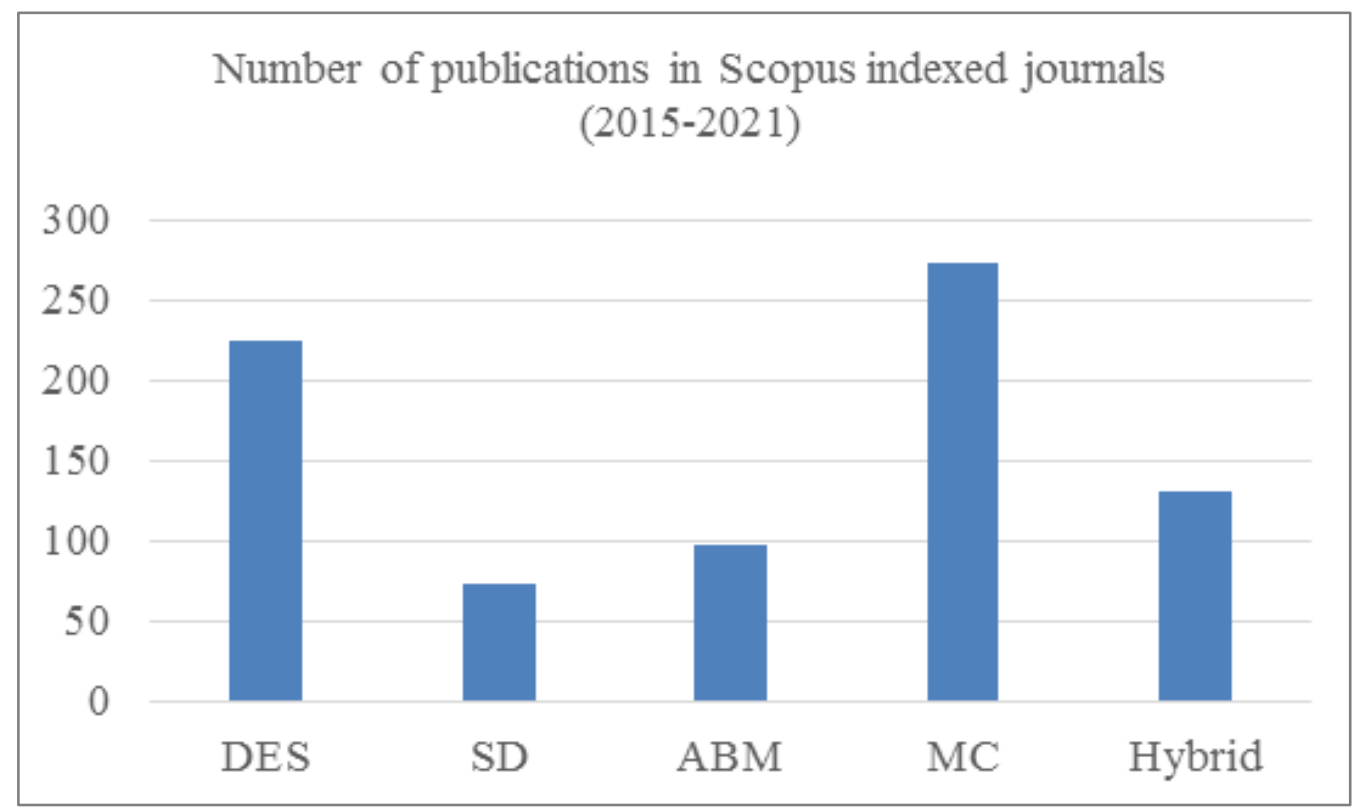

Figure 2. Frequency of the number of Scopus indexed journal publications of five simulation types for the period of 2015 to 2021.

\section{Conclusions}

In summary, DES focuses on the problems of queuing and processing, SD considers the world as a feedback system, ABM looks at an environment populated with autonomous beings, and Monte Carlo simulation is more about risk and statistical analysis. The combination or hybridization of any two or more types is needed when the problems could not be solved by any single model alone. In the future, we plan and hope to construct a decision support system that can be used in selecting simulation types for specific healthcare system problems.

\section{Acknowledgement}

This research is funded by Universiti Utara Malaysia under a Leadership Development Scheme (LEADS) Grant with S/O Code 12409.

\section{Conflict of Interest}

The authors declare that they have no conflict of interests.

\section{REFERENCES}

[1] B. Sobolev, "Linking operations and health services research,” Clin. Investig. Med. (Medecine Clin. Exp., vol. 28, no. 1, pp. 277-310, 2005.
[2] K. Walshe and T. G. Rundall, "Evidence-based management: from theory to practice in health care.," Milbank Q., vol. 79, no. 3, pp. 429-57, IV-V, 2001, doi: 10.1111/1468-0009.00214.

[3] S. Watt, W. Sword, and P. Krueger, "Implementation of a health care policy: An analysis of barriers and facilitators to practice change,” BMC Health Serv. Res., vol. 5, 2005, doi: 10.1186/1472-6963-5-53.

[4] R. G. Ingalls, "Introduction to simulation," in Proceedings of the 2013 Winter Simulation Conference - Simulation: Making Decisions in a Complex World, WSC 2013, 2013, pp. 291-305, doi: 10.1109/WSC.2013.6721428.

[5] J. R. Wilson, D. T. Brunner, and J. J. Swain, "The Winter Simulation Conference: the premier forum on simulation practice and theory,” ACM SIGSIM Simul. Dig., vol. 25, no. 3, pp. 6-10, 1996.

[6] W. H. Iskander and D. M. Carter, “A simulation model for a same day care facility at a university hospital,” Institute of Electrical and Electronics Engineers (IEEE), 1991.

[7] M. A. Draeger, “An emergency department simulation model used to evaluate alternative nurse staffing and patient population scenarios," in Proceedings of the 24th conference on Winter simulation, 1992, pp. 1057-1064.

[8] J. K. Canner, Y.-P. Chiang, and J. C. Javitt, “A Monte Carlo based simulation network model for a chronic progressive disease: the case of diabetic retinopathy," in Proceedings of the 24th conference on Winter simulation, 1992, pp. 10411049.

[9] M. S. Roberts, "Markov process-based Monte Carlo simulation: a tool for modeling complex disease and its application to the timing of liver transplantation," in Proceedings of the 24th conference on winter simulation, 1992, pp. 1034-1040.

[10] J. Kuljis, R. J. Paul, and L. K. Stergioulas, “Can health care 
benefit from modeling and simulation methods in the same way as business and manufacturing has?,” in Proceedings Winter Simulation Conference, 2007, pp. 1449-1453, doi: 10.1109/WSC.2007.4419755.

[11] K. Chahal, "A generic framework for hybrid simulation in healthcare,” Brunel University, 2009.

[12] P. Barton, S. Bryan, and S. Robinson, "Modelling in the economic evaluation of health care: selecting the appropriate approach.," J. Health Serv. Res. Policy, vol. 9, no. 2, pp. 110-118, Apr. 2004, doi: 10.1258/13558190432 2987535.

[13] M. Pidd, Computer Simulation in Management Science, 5th ed. Chichester: John Wiley and Sons Ltd, 2004.

[14] T. Lorenz and A. Jost, "Towards an orientation framework in multi-paradigm modeling," in Proceedings of the 24th International Conference of the System Dynamics society, 2006, pp. 2134-2151.

[15] S. V. Kovalchuk, A. A. Funkner, O. G. Metsker, and A. N. Yakovlev, "Simulation of patient flow in multiple healthcare units using process and data mining techniques for model identification,” J. Biomed. Inform., vol. 82, pp. 128-142, Jun. 2018, doi: 10.1016/J.JBI.2018.05.004.

[16] J. Morecroft and S. Robinson, "Explaining puzzling dynamics: A comparison of system dynamics and discrete-event simulation," in Discrete-Event Simulation and System Dynamics for Management Decision Making, 2014.

[17] S. Brailsford and N. Hilton, "A comparison of discrete event simulation and system dynamics for modelling health care systems,” Proc. from ORAHS 2000, 2001.

[18] A. A. Tako and S. Robinson, "Comparing discrete-event simulation and system dynamics: Users' perceptions," $J$. Oper. Res. Soc., 2009, doi: 10.1057/palgrave.jors.2602566.

[19] D. Terry, H. Nguyen, A. J. Perkins, and B. Peck, "Supervision in healthcare: A critical review of the role, function and capacity for training," Universal Journal of Public Health, vol. 8, no. 1, pp. 1-14, 2020, doi: 10.13189/ujph.2020.080101.

[20] T. Al-Hawari, A. Khanfar, A. Mumani, and O. Bataineh, “A Simulation-Based Framework for Evaluation of Healthcare Systems with Interacting Factors and Correlated Performance Measures,” Arab. J. Sci. Eng., 2021, doi: 10.1007/s13369-021-05937-5.

[21] M. Ordu, E. Demir, and S. Davari, "A hybrid analytical model for an entire hospital resource optimisation," Soft Comput., vol. 25, no. 17, pp. 11673-11690, 2021, doi: $10.1007 / \mathrm{s} 00500-021-06072-x$.

[22] M. Gul, A. Fuat Guneri, and M. M. Gunal, "Emergency department network under disaster conditions: The case of possible major Istanbul earthquake,” J. Oper. Res. Soc., vol. 71, no. 5, pp. 733-747, May 2020, doi: 10.1080/01605682.2019.1582588.

[23] N. Li, Y. Zhang, D. Teng, and N. Kong, "Pareto optimization for control agreement in patient referral coordination,” Omega, vol. 101, p. 102234, Jun. 2021, doi: 10.1016/J.OMEGA.2020.102234.
[24] [24] C. Gonul Kochan, D. R. Nowicki, B. Sauser, and W. S. Randall, "Impact of cloud-based information sharing on hospital supply chain performance: A system dynamics framework,” Int. J. Prod. Econ., vol. 195, pp. 168-185, Jan. 2018, doi: 10.1016/J.IJPE.2017.10.008.

[25] T. Bolt, S. Bayer, M. Kapsali, and S. Brailsford, "An analytical framework for group simulation model building," Heal. Syst., vol. 10, no. 3, pp. 198-211, Jul. 2021, doi: 10.1080/20476965.2020.1740613.

[26] R. Kazemi, A. Mosleh, and M. Dierks, “A Hybrid Methodology for Modeling Risk of Adverse Events in Complex Health-Care Settings,” Risk Anal., vol. 37, no. 3, pp. 421-440, Mar. 2017, doi: https://doi.org/10.1111/risa.1 2702.

[27] I. Garcia-Magarino, R. Lacuesta, and J. Lloret, "Agent-Based Simulation of Smart Beds with Internet-of-Things for Exploring Big Data Analytics," IEEE Access, vol. 6, pp. 366-379, 2017, doi: 10.1109/ACCESS.2017.2764467.

[28] Z. Liu, D. Rexachs, F. Epelde, and E. Luque, "An agent-based model for quantitatively analyzing and predicting the complex behavior of emergency departments,” J. Comput. Sci., vol. 21, pp. 11-23, Jul. 2017, doi: 10.1016/J.JOCS.2017.05.015.

[29] M. M. Yousefi, M. M. Yousefi, F. S. Fogliatto, R. P. M. Ferreira, and J. H. Kim, "Simulating the behavior of patients who leave a public hospital emergency department without being seen by a physician: a cellular automaton and agent-based framework," Brazilian J. Med. Biol. Res., vol. 51, no. 3, Jan. 2018, doi: 10.1590/1414-431x20176961.

[30] M. Alauddin, F. Khan, S. Imtiaz, S. Ahmed, and P. Amyotte, "Pandemic risk management using engineering safety principles,” Process Saf. Environ. Prot., vol. 150, pp. 416432, Jun. 2021, doi: 10.1016/J.PSEP.2021.04.014.

[31] S. Hassanhosseini, M. R. Taban, J. Abouei, and A. Mohammadi, "Improving performance of indoor localization using compressive sensing and normal hedge algorithm,” Turkish J. Electr. Eng. Comput. Sci., vol. 28, no. 4, pp. 2143-2157, 2020, doi: 10.3906/ELK-1911-45.

[32] K. H. Lee, F. Dominici, D. Schrag, and S. Haneuse, "Hierarchical Models for Semicompeting Risks Data With Application to Quality of End-of-Life Care for Pancreatic Cancer," J. Am. Stat. Assoc., vol. 111, no. 515, pp. 10751095, Jul. 2016, doi: 10.1080/01621459.2016.1164052.

[33] A. Parolini, W. W. Tan, and A. Shlonsky, "Decision-based models of the implementation of interventions in systems of healthcare: Implementation outcomes and intervention effectiveness in complex service environments," PLoS One, vol. 14, no. 10, p. e0223129, Oct. 2019, doi: 10.1371/journal.pone.0223129.

[34] S. C. Brailsford, T. Eldabi, M. Kunc, N. Mustafee, and A. F. Osorio, "Hybrid simulation modelling in operational research: A state-of-the-art review," Eur. J. Oper. Res., vol. 278, no. 3, pp. 721-737, Nov. 2019, doi: 10.1016/J.EJOR.2018.10.025.

[35] J. H. Powell and N. Mustafee, "Widening requirements capture with soft methods: An investigation of hybrid M\&amp;S studies in health care,” J. Oper. Res. Soc., vol. 68, no. 10, pp. 1211-1222, 2017, doi: 10.1057/s41274-016-01 47-6. 
[36] J. Powell and N. Mustafee, "Soft or approaches in problem formulation stage of a hybrid M\&amp;S study," in Proceedings - Winter Simulation Conference, 2015, vol. 2015-Janua, pp. 1664-1675, doi: 10.1109/WSC.2014.7020 017.

[37] J. Zulkepli and T. Eldabi, "Towards a framework for conceptual model hybridization in healthcare," in Proceedings - Winter Simulation Conference, 2016, vol. 2016-Febru, pp. 1597-1608, doi: 10.1109/WSC.2015.7408 280.
[38] A. Harper, N. Mustafee, and M. Feeney, “A hybrid approach using forecasting and discrete-event simulation for endoscopy services," in Proceedings - Winter Simulation Conference, 2017, pp. 1583-1594, doi: 10.1109/WSC.2017.8247899.

[39] M. Fakhimi, L. K. Stergioulas, and N. Mustafee, “An investigation of Hybrid Simulation for modeling sustainability in healthcare," in Proceedings - Winter Simulation Conference, 2016, vol. 2016-Febru, pp. 15851596, doi: 10.1109/WSC.2015.7408279. 